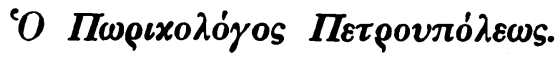

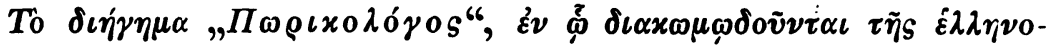

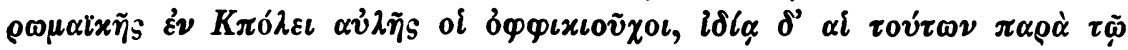

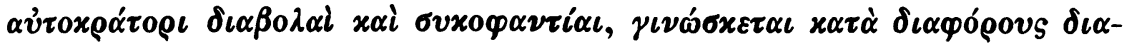

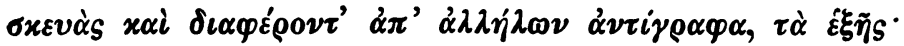

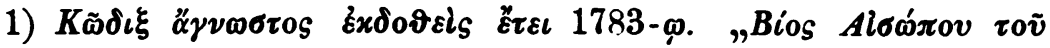

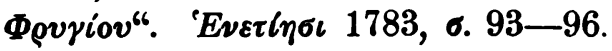

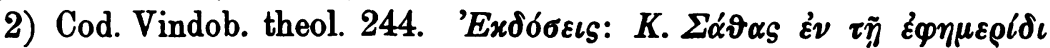
$K \lambda \varepsilon \iota \dot{\omega}, 1871$, $\alpha \varrho \iota \vartheta .516$. W. Wagner, Carmina graeca medii aevi.

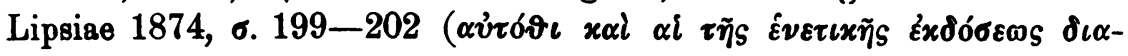

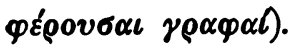

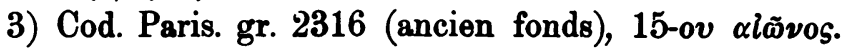

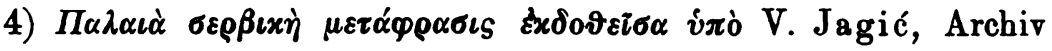

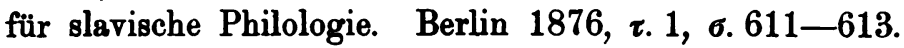

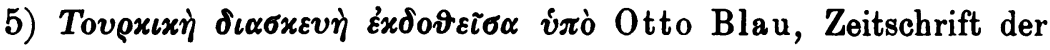
morgenländischen Gesellschaft, 1874, $\tau .28, \sigma .569 x \dot{\varepsilon}$.

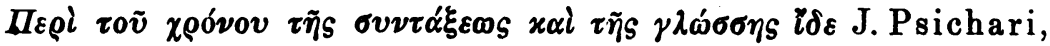
Essais de grammaire historique néo-grecque. Paris $1886-1889$, r. 1 , б. 18. Tб $\mu .2$, б. $175-176$.

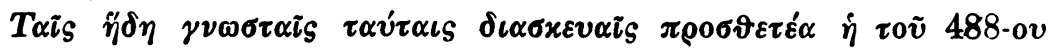

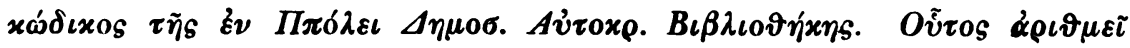

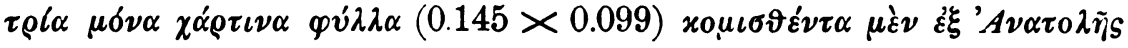

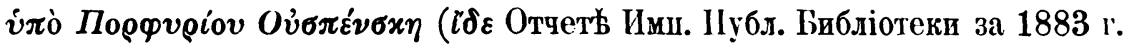

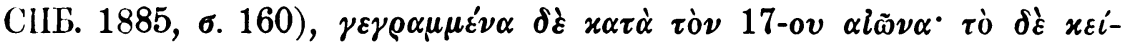

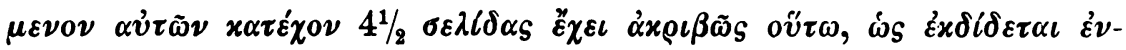

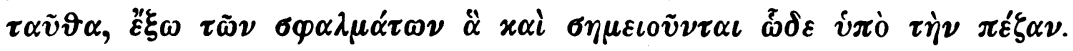

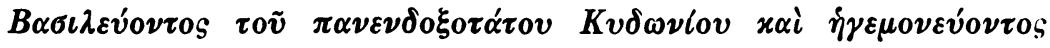

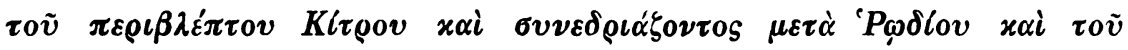

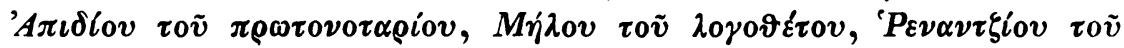

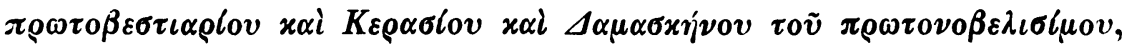

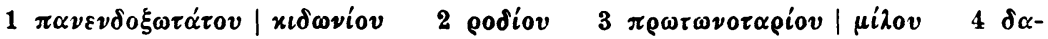
$\mu \alpha \sigma x$ v่vov | $\pi \rho \omega \tau o \beta \varepsilon \lambda \varepsilon \sigma i o v$ 


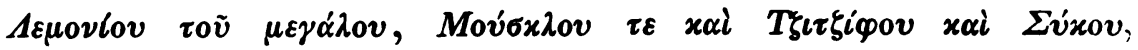

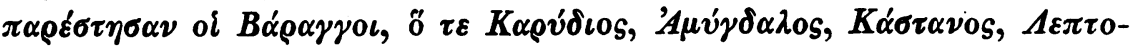

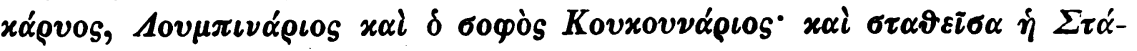

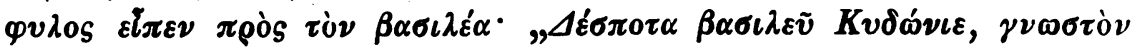

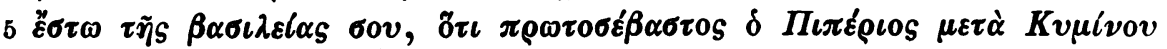

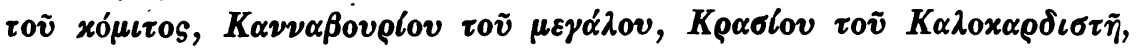

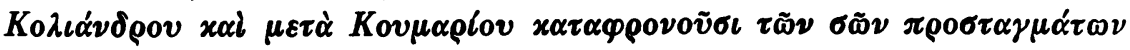

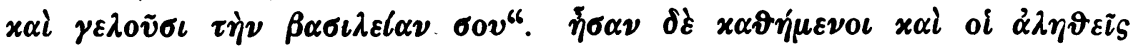

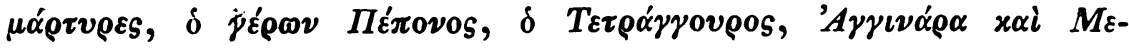

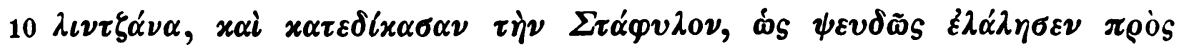

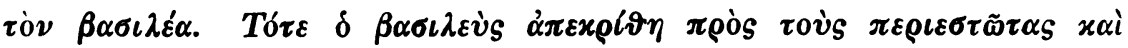

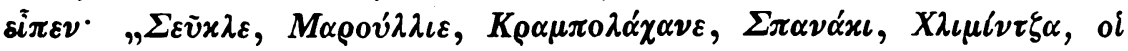

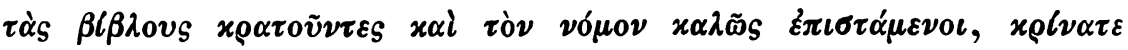

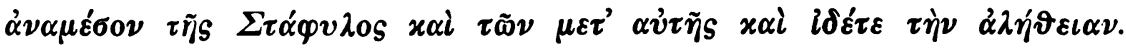

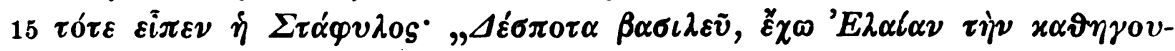

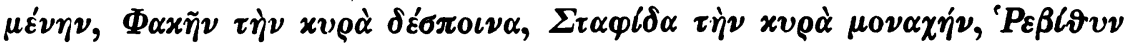

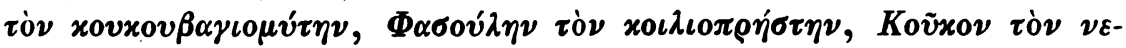

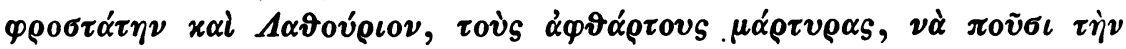

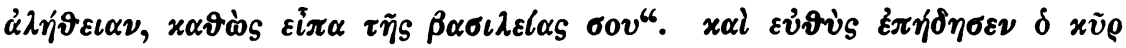

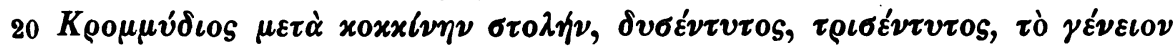

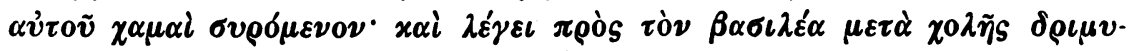

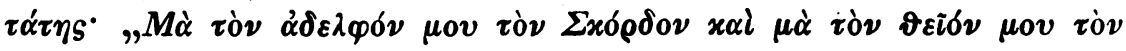

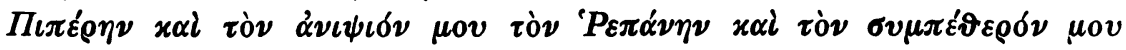

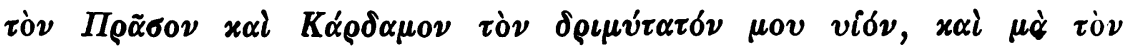

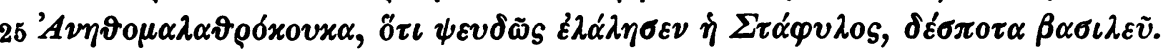

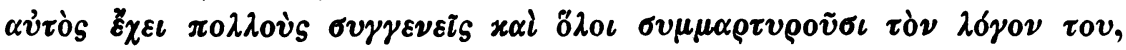

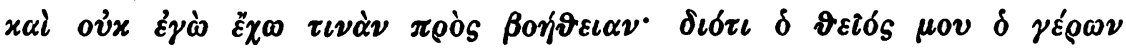

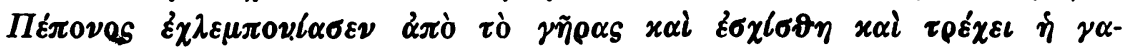

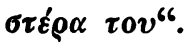

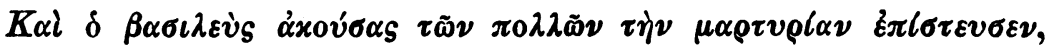

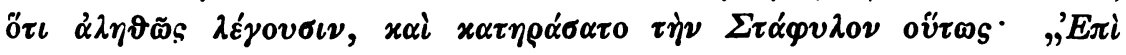

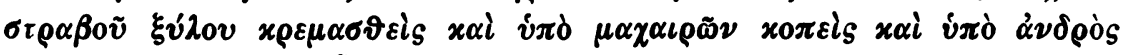

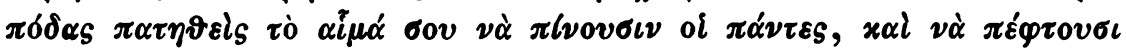

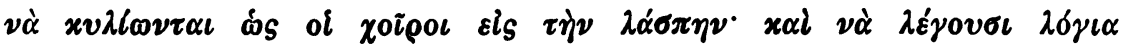

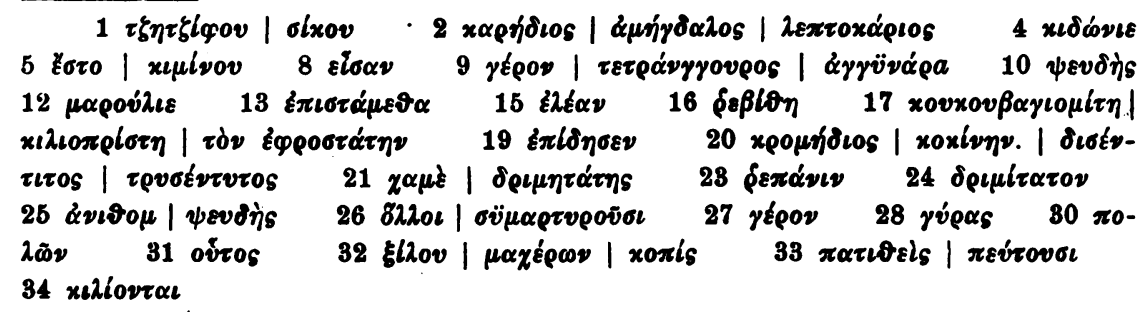




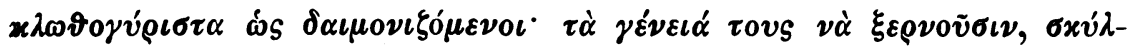

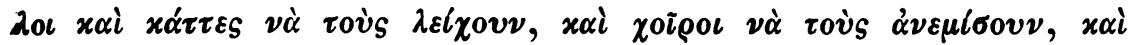

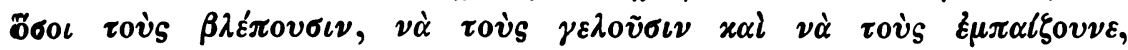

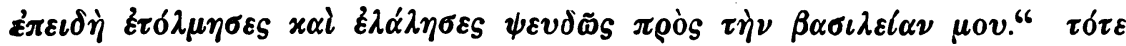

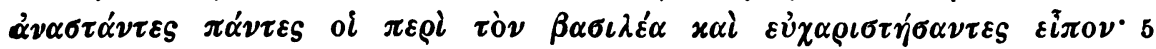

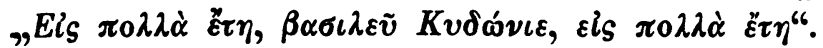

'Ev $\Pi \pi \delta ́ \lambda \varepsilon \iota$.

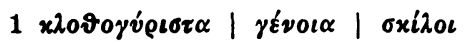

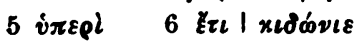

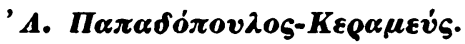

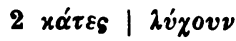

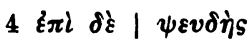

\section{Eine unbemerkte altchristliche Akrostichis.}

In der BZ XVIII (1909) 511-515 hat P. Maas eine Untersuchung über die Metrik der Thaleia des Areios veröffentlicht. Der einzige zusammenhängende Rest des Gedichtes, den wir besitzen, sind die sieben Anfangszeilen. Soviel ich sehe, hat noch niemand bemerkt,

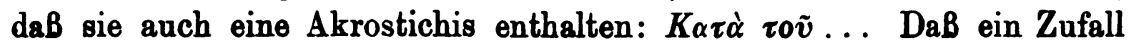
uns hier neckt, ist wohl nicht anzunehmen; der Zweck (und wohl auch der zu ergänzende Name) ist leicht zu erraten: Areios wollte böswillige Einschiebungen verhindern, die das Gedicht verändern und von den Gegnern gegen ihn ausgebeutet werden könnten. Die übrigen Fragmente zeigen, wie zu erwarten, keine Spuren dieser Kunstform. Immerhin haben wir ein Beispiel aus der christlich-griechischen Literatur gewonnen, das zeitlich nicht allzuspät nach Methodios von Tyros anzusetzen ist.

Schweinfurt.

W. Weyh. 